\title{
Effect of holding pressure on density and cooling rate of cast Al-Si alloy during additive pressure casting
}

\author{
Zhen Fan', Wei Song', *Hua-rui Zhang', Bao-sheng Zhou ${ }^{2}$, Xiao-yan Wu' ${ }^{1}$, Li-na Jia ${ }^{1}$, Hu Zhang ${ }^{1,3}$ \\ 1. School of Materials Science and Engineering, Beihang University, Beijing 100191, China \\ 2. Qingdao Research Institute of Beihang Universtiy, Qingdao 266000, China \\ 3. Ningbo Institute of Technology, Beihang University, Ningbo 315832, China
}

\begin{abstract}
The cast Al-Si alloy was fabricated using the Additive Pressure Casting (APC) method. The effects of holding pressure from 50 to $400 \mathrm{kPa}$ on the density, cooling rate, and mechanical properties of the alloy, and the corresponding mechanism were discussed. The results indicate that the application of high holding pressure (300 $\mathrm{kPa}$ ) enhances the feeding ability of the alloy, leading to an increase of the density. Meanwhile, the cooling rate of the alloy is increased by $100 \%$. In addition, the tensile testing results show that the increase of holding pressure from 50 to $300 \mathrm{kPa}$ improves the tensile strength and elongation of the alloy by $6.2 \%$ and $81.3 \%$, respectively. However, excessive holding pressure $(400 \mathrm{kPa})$ might lower the density and cooling rate of the alloy due to the feeding channels being blocked.
\end{abstract}

Key words: holding pressure; cast Al-Si alloy; density; cooling rate; mechanical properties; additive pressure casting CLC numbers: TG146.21 Document code: $\mathrm{A}$

Article ID: 1672-6421(2019)06-363-08

\begin{abstract}
A utomotive lightweightedness is an effective way to save energy and reduce emissions. One of the main methods to reduce automotive weight is to produce auto parts using light alloys such as aluminum alloys and magnesium alloys instead of steels ${ }^{[1-4]}$. Among all the light alloys, cast Al-Si alloy is a great candidate in the automobile field owing to its outstanding casting properties such as good fluidity, small line contraction tendency, and high corrosion resistance ${ }^{[5-7]}$. At present, low pressure die casting (LPDC) is one of the most commonly used methods for producing Al-Si alloy castings ${ }^{[1]}$. LPDC is characterized by steady and antigravity filling and solidification under pressure ${ }^{[8]}$ which is called holding pressure. However, the mechanical properties of Al-Si alloys currently cannot satisfy further weight-reduction requirements. It's of great importance to further refine the microstructure and improve the tensile properties of Al-Si alloys.
\end{abstract}

Some researchers increased the holding pressure in

*Hua-rui Zhang

Female, born in 1984, Ph.D, Lecturer. Research interests: cast aluminum alloys with advanced properties and purification of surperalloys. Her academic research has led to the publication of more than 30 technical papers.

E-mail: huarui@buaa.edu.cn

Received: 2019-07-28; Accepted: 2019-10-25 casting process to enhance the feeding ability of the alloy. It was found that the feeding ability was improved and the casting defects of the alloys were reduced by increasing the pressure to $90-200 \mathrm{MPa}$, thus the microstructure and mechanical properties of the alloys were optimized ${ }^{[9-12]}$. Unfortunately, the holding pressure in LPDC is generally lower than $100 \mathrm{kPa}$, limited by the technique and equipment ${ }^{[13]}$. As a result, casting defects such as shrinkage cavities can form easily due to the insufficient feeding force ${ }^{[14]}$. Giulio Timelli et al. ${ }^{[8]}$ found that when the holding pressure is lower than 50 $\mathrm{kPa}$, increasing the holding pressure has little impact on optimizing the microstructure and improving the performance of Al-Si alloys.

In order to improve the feeding ability of the alloy, an advanced casting method named Additive Pressure Casting (APC) based on LPDC has been developed ${ }^{[15]}$. Compared to LPDC, a holding pressure of more than $500 \mathrm{kPa}$ can be applied during APC, so that the feeding ability of the alloy is greatly enhanced. Previous experiments have found that when the holding pressure is increased from 85 to $300 \mathrm{kPa}$, the microstructure of A356 alloy is refined, the mechanical properties are improved, and the fracture mode is changed from ductile-brittle mixed fracture to ductile fracture ${ }^{[16,17]}$.

However, the effect of the holding pressure higher 
than $300 \mathrm{kPa}$ on the microstructure and properties of APC Al-Si alloys has not been reported yet. What's more, the mechanism of the effect of holding pressure on Al-Si alloy is still unclear. In this study, the effect of holding pressure from 50 to $400 \mathrm{kPa}$ on the microstructure and mechanical properties of A356 alloy during APC was studied. Furthermore, the action mechanism of the holding pressure was studied by density analysis method.

\section{Experimental procedure}

The material studied in this work is A356 alloy with the chemical composition listed in Table 1. In order to research the effect and corresponding interaction mechanism of holding pressure on the alloy, a special mold was designed and the geometry of the sample formed using APC is shown in Fig. 1 (a). The thickness of the sample reduced gradually from the center to the edges, which can ensure the sample's solidifying from the ends of the mold to the gate portion in sequence. The APC process can be divided into 7 stages: rising, filling, shelling pressurization, holding pressure for shelling, crystallization pressurization, holding pressure for crystallization, and pressure relief cooling. The pressure vs. time curve of APC is shown in Fig. 1 (b). The holding pressures selected for this experiment were 50, 80, 200, 300 and $400 \mathrm{kPa}$, respectively. After casting, T6 heat treatment was conducted using the following schedule: (1) Solution treated at $535^{\circ} \mathrm{C}$ for $600 \mathrm{~min}$; (2) Water quenched at $70{ }^{\circ} \mathrm{C}$ for $20 \mathrm{~min}$; (3) Artificially aged at $170{ }^{\circ} \mathrm{C}$ for $420 \mathrm{~min}$.

Table 1: Chemical composition of experiment Al-Si alloy (wt.\%)

\begin{tabular}{cccccccccc} 
Si & $\mathrm{Mg}$ & $\mathrm{Fe}$ & $\mathrm{Cu}$ & $\mathrm{Ti}$ & $\mathrm{Sr}$ & $\mathrm{Zn}$ & $\mathrm{Mn}$ & Al \\
\hline 7.25 & 0.43 & 0.11 & 0.003 & 0.16 & 0.017 & 0.008 & 0.002 & Bal.
\end{tabular}

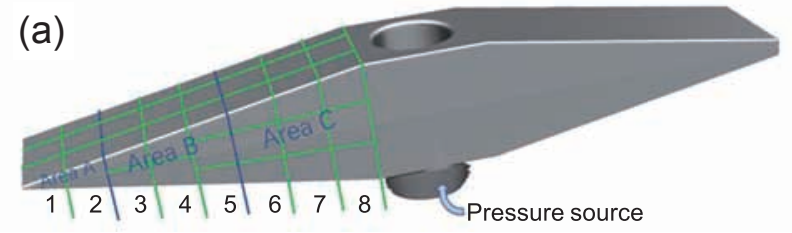

(b)

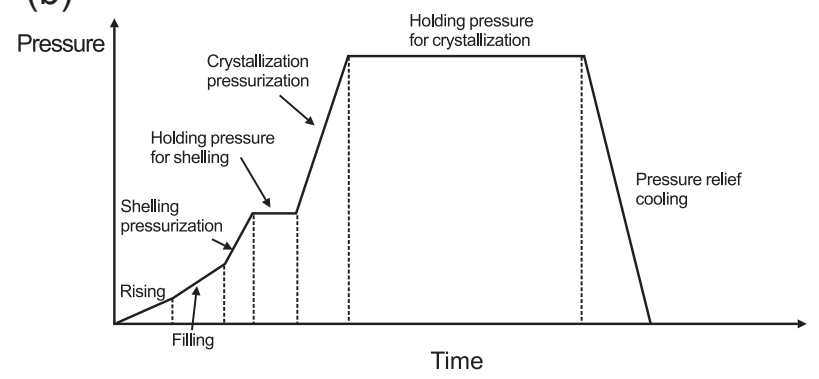

Fig. 1: (a) Geometry of sample; (b) Typical pressure-time curve of APC

To study the effect of holding pressure on various parts of the sample, the density of each part of the samples, divided according to the lines shown in Fig. 1 (a), was measured by the Archimedes drainage method. After that, the density of each part was fitted using the Origin software to get the density distribution of the samples.

Areas A, B, and C, as shown in Fig. 1 (a), at different distances from the pressure source, were selected for further analysis. Tensile test specimens with a diameter of $6 \mathrm{~mm}$ were obtained in Areas B and C according to the ASTM E8M standard, then the tensile test was performed at room temperature using an SRE M\&X tensile machine with a tensile rate of $1 \mathrm{~mm} \cdot \mathrm{min}^{-1}$. The ultimate tensile strength (UTS), yield strength (YS) and elongation (E) of the specimens were determined based on the average value of 3 measurements.
Specimens for microstructure analysis were taken from Areas $\mathrm{A}, \mathrm{B}$ and $\mathrm{C}$, and ground using grinding paper ranging from 320 to 3000 grit. Then, the samples were polished with diamond polishing agents of $5 \mu \mathrm{m}$ and $1 \mu \mathrm{m}$ in sequence. The specimens were then ultrasonically cleaned and etched using $5 \% \mathrm{HF}$ aqueous solution for $20 \mathrm{~s}$. The microstructure of the specimens was observed with an optical microscope (Shang Guang 9XF), and then the secondary dendrite arm spacing (SDAS) and porosity were measured using Image Pro Plus metallographic analysis software.

\section{Results}

\subsection{Effect of holding pressure on density}

Figure 2 shows the variation of the average density of Areas $\mathrm{A}, \mathrm{B}$ and $\mathrm{C}$ with the holding pressure. With the increase of holding pressure, the density of Area A does not change much, while the density of Areas B and C increases more obviously. However, the density of Area $\mathrm{C}$ decreases with the holding pressure further increasing from 300 to $400 \mathrm{kPa}$.

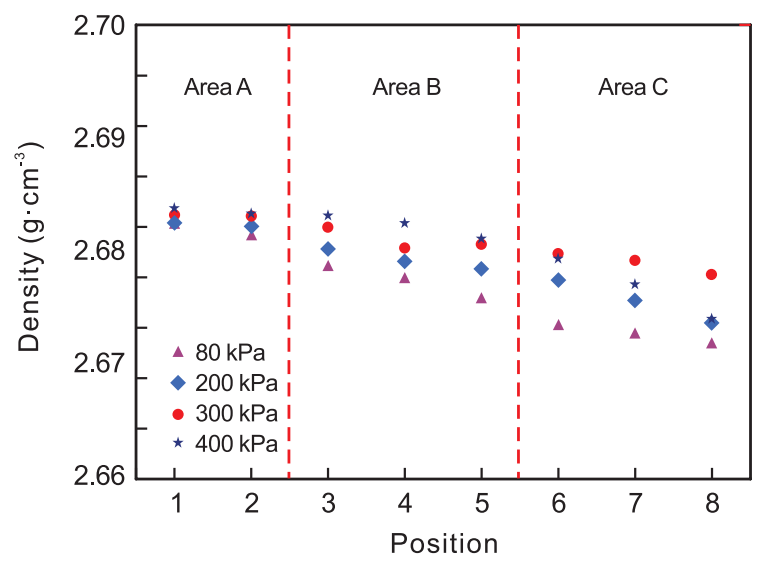

Fig. 2: Effect of holding pressure on density of Al-Si alloy 
The mold temperatures measured by thermocouples as shown in Fig. 3 indicate that the temperature of the lower mold is higher than the upper one. Figure 4 shows the density distribution of the samples at holding pressure of $80 \mathrm{kPa}$ and $300 \mathrm{kPa}$. It can be seen that when the holding pressure is 80 $\mathrm{kPa}$, the upper part of the sample is denser than the lower one. In the axial direction, Area A, which is far from the gate, is denser, while a loose area appears in Area B, and the action distance of holding pressure is about $65 \mathrm{~mm}$ along the axis.

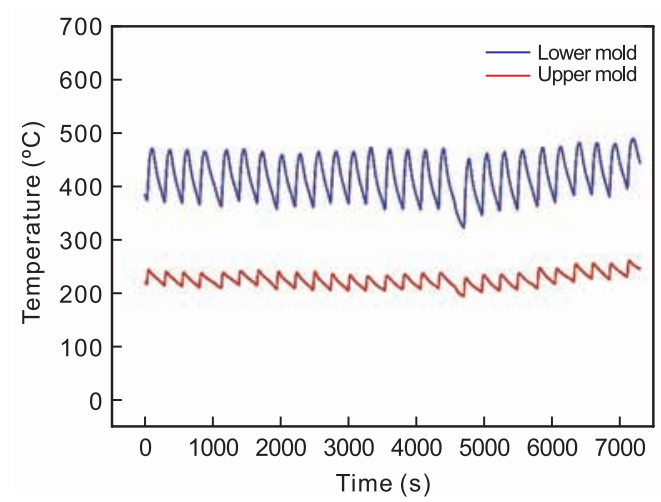

Fig. 3: Temperature curve of APC casting mold

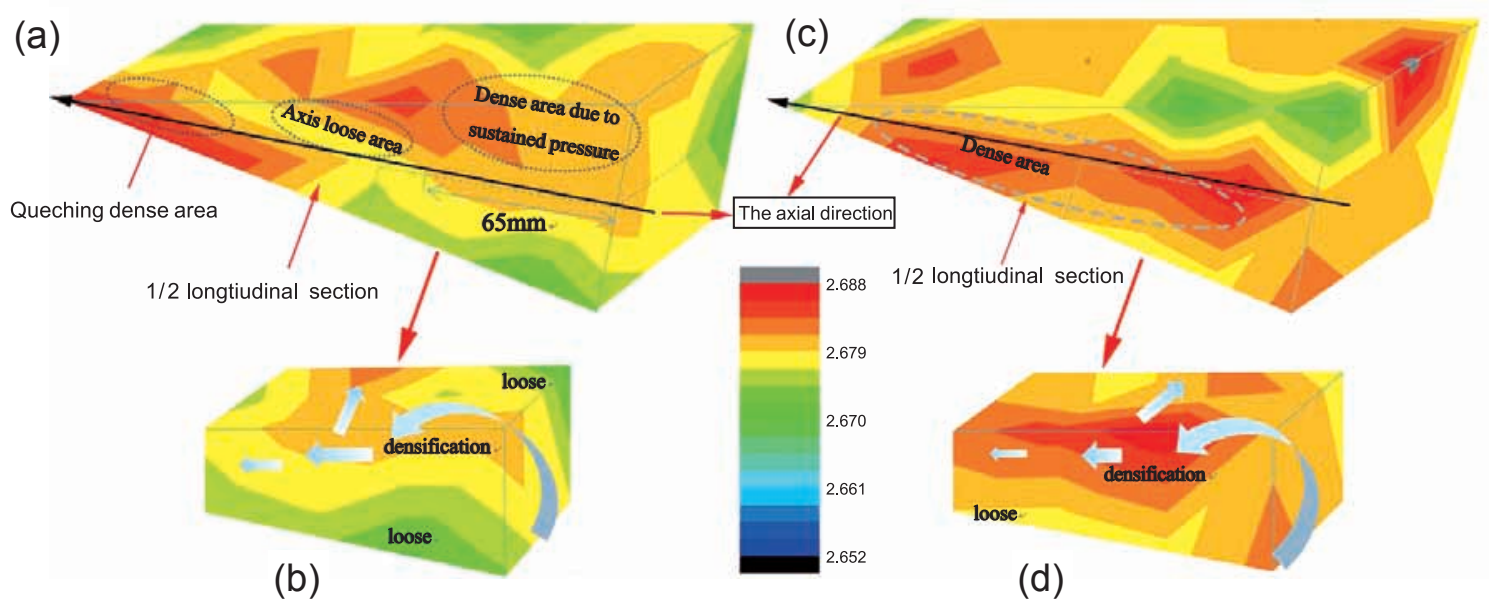

Fig. 4: Density distribution of samples at $80 \mathrm{kPa}$ (a and b) and $300 \mathrm{kPa}$ (c and d)

When the holding pressure increases to $300 \mathrm{kPa}$, it can affect almost all areas of the sample, as shown in Fig. 4 (c), and there is no loose area along the axial. What's more, the lower half of the sample is denser than the upper one, which is contrary to the density distribution at $80 \mathrm{kPa}$. The pressure resource is in the lower mold, so the holding pressure has a greater influence on the lower half of the sample than the upper one. When a high pressure $(300 \mathrm{kPa})$ is applied, the lower half of the sample becomes denser than the upper one, which indicates that the holding pressure has a great influence on the density of the alloy. It can also be seen from Fig. 4 (b) and Fig. 4 (d) that in the main action area of the holding pressure (Area $\mathrm{C}$ ), the effect of pressure weakens as the distance from the pressure source becomes longer. In addition, the range of action extends with the increase of the holding pressure.

Figure 5 shows the variation of porosity with the change of holding pressure in different areas of the samples. It can be obtained that with the increase of holding pressure, the porosities of Areas B and $\mathrm{C}$ are significantly reduced. The porosity of Area B is $0.44 \pm 0.02 \%$ at the holding pressure of $400 \mathrm{kPa}$, which is decreased by $60.4 \%$ compared to that at $50 \mathrm{kPa}$; while the porosity of Area $\mathrm{C}$ reaches a minimum of $0.53 \pm 0.09 \%$ at $300 \mathrm{kPa}$, which is $57.6 \%$ lower than that at $50 \mathrm{kPa}$. The increase of holding pressure is very effective for reducing porosity defects. The porosity of Area A is much smaller than that of Areas B and C, and the variation of which, with the change of pressure, can be ignored. This is consistent with the results of density, therefore, subsequent studies on cooling rate and mechanical properties are mainly focused on Areas B and C.

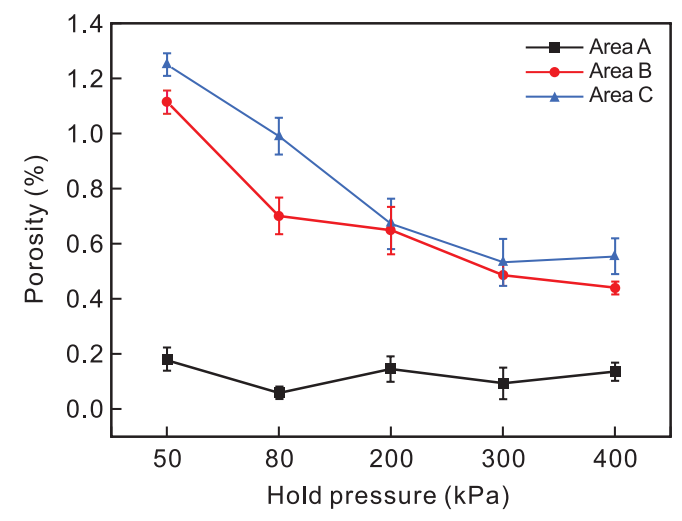

Fig. 5: Porosities of various areas at different holding pressures

\subsection{Effect of holding pressure on cooling rate}

Figure 6 shows the SDAS and cooling rate of Areas B and $\mathrm{C}$ under different holding pressures. The SDAS of Area B reduces from $33.48 \pm 1.41 \mu \mathrm{m}$ to $26.54 \pm 1.15 \mu \mathrm{m}$ with the holding pressure increasing from 50 to $400 \mathrm{kPa}$, which is a reduction of $20.7 \%$. The SDAS of Area $\mathrm{C}$ reaches a minimum 
of $32.94 \pm 1.36 \mu \mathrm{m}$ at $300 \mathrm{kPa}$, which is $19.8 \%$ lower than that at $50 \mathrm{kPa}$, while the SDAS of Area $\mathrm{C}$ becomes larger when the pressure increases to $400 \mathrm{kPa}$. This is consistent with the ascast microstructure shown in Fig. 7. Figure 7 indicates that the primary $\alpha$-Al dendrites become finer as the holding pressure increasing from 50 to $300 \mathrm{kPa}$, but when the holding pressure is higher than $300 \mathrm{kPa}$, the $\alpha-\mathrm{Al}$ dendrites become coarser.
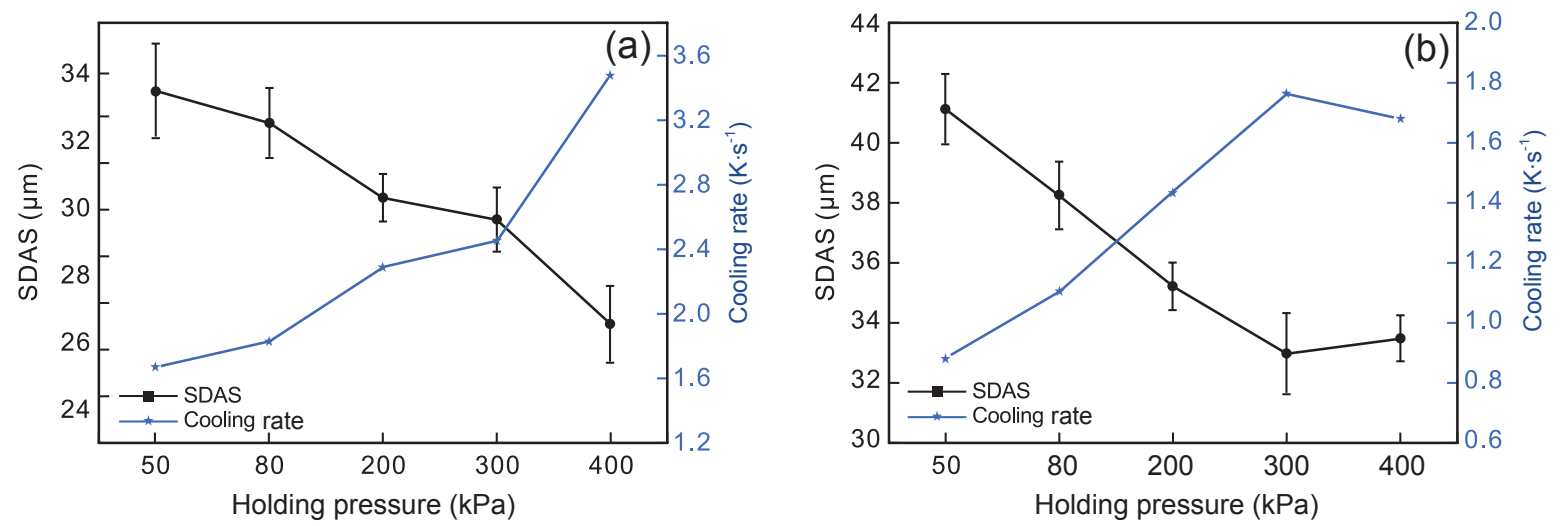

Fig. 6: Effect of holding pressure on SDAS and cooling rate of Area B(a) and Area C (b)
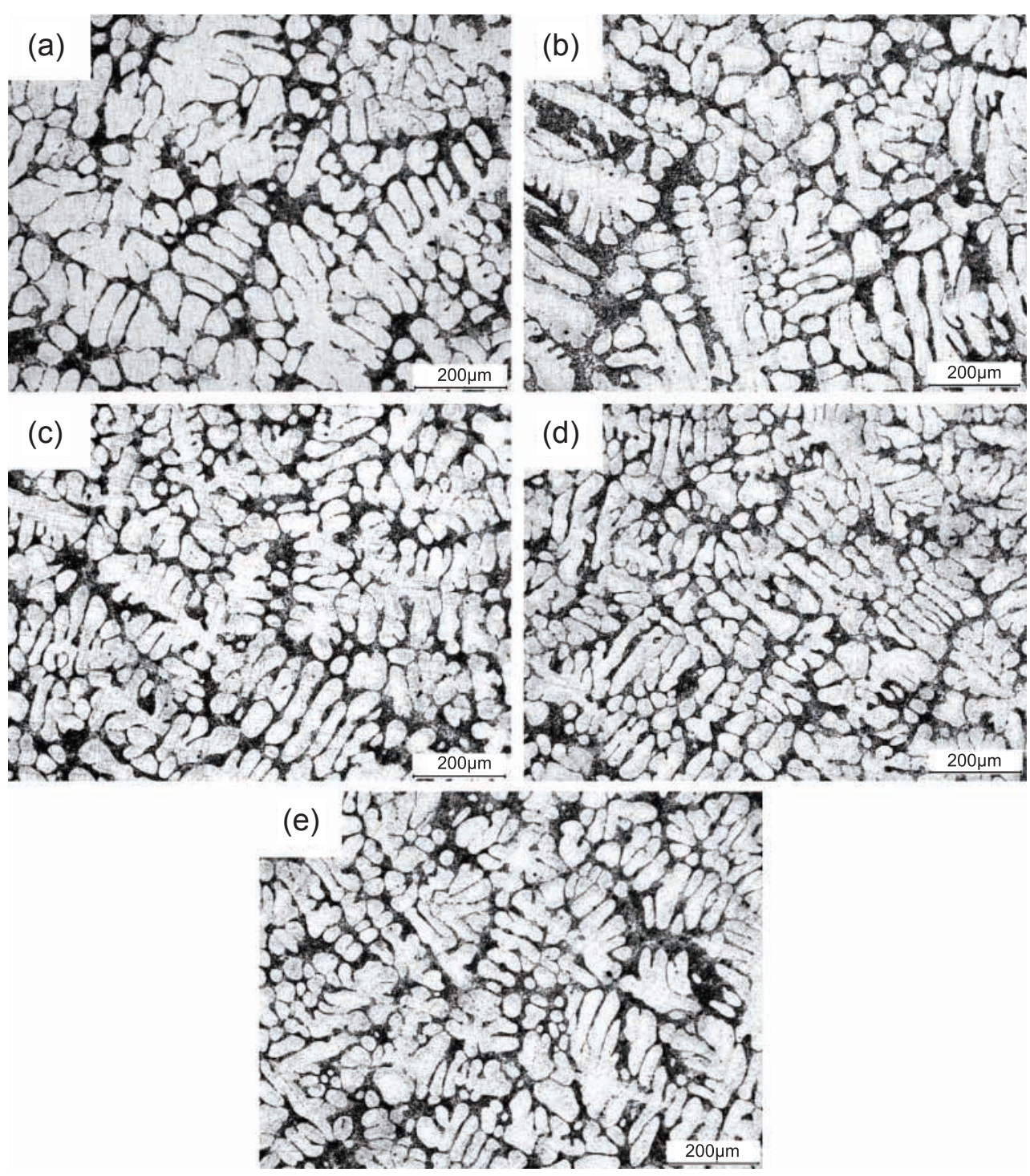

Fig. 7: As-cast microstructures of Area C at different pressures: (a) $50 \mathrm{kPa}$; (b) $80 \mathrm{kPa}$; (c) 200 $\mathrm{kPa}$; (d) $300 \mathrm{kPa}$; (e) $400 \mathrm{kPa}$ 
SDAS is related to the cooling rate, and can be calculated according to Eq. (1) ${ }^{[18] \text { : }}$

$$
\lambda_{2}=39.4 R^{-0.317}
$$

where $\lambda_{2}$ represents the size of SDAS and $R$ represents the mean cooling rate of the primary $\alpha-\mathrm{Al}$ dendrites during solidification.

According to the results shown in Fig. 6, with the holding pressure improving from 50 to $400 \mathrm{kPa}$, the cooling rate of Area B increases from $1.67 \mathrm{~K} \cdot \mathrm{s}^{-1}$ to $3.48 \mathrm{~K} \cdot \mathrm{s}^{-1}$, which is an increase of $108.4 \%$. The cooling rate of Area $\mathrm{C}$ reaches a maximum of $1.76 \mathrm{~K} \cdot \mathrm{s}^{-1}$ at the holding pressure of $300 \mathrm{kPa}$, which is increased by $100 \%$ compared to that at $50 \mathrm{kPa}$.

\subsection{Mechanical properties}

Figure 8 shows the mechanical properties of Areas B and C under different pressures, from which a significant improvement in elongation (E) and certain improvements in ultimate tensile strength (UTS) and yield strength (YS) are clearly noticed with the increase of holding pressure. The UTS and E of Area $B$ reaches the maximum of $337.9 \pm 2.7 \mathrm{MPa}$ and $8.4 \pm 0.2 \%$ when the holding pressure is $400 \mathrm{kPa}$, which are respectively $4.7 \%$ and $50 \%$ higher than those exhibited by $50 \mathrm{kPa}$. The YS fluctuates with the increase of holding pressure, and reaches the maximum of $278.6 \pm 2.3 \mathrm{MPa}$ at $400 \mathrm{kPa}$. In general, Area $\mathrm{B}$ achieves the best performance at the holding pressure of $400 \mathrm{kPa}$.

The UTS and E of Area C increases with the change of holding pressure from 50 to $300 \mathrm{kPa}$, which are $332 \pm 3.8 \mathrm{MPa}$ and $6.7 \pm 0.6 \%$ when the holding pressure is $300 \mathrm{kPa}, 6.2 \%$ and $81.3 \%$ higher than that exhibited by $50 \mathrm{kPa}$, respectively. When the holding pressure reaches $400 \mathrm{kPa}$, the UTS and E decrease, and the best performance is obtained at the holding pressure of $300 \mathrm{kPa}$. The variation of the mechanical properties of Areas B and C with holding pressure is in good agreement with the changing tendency of SDAS exhibited in Section 2.2.
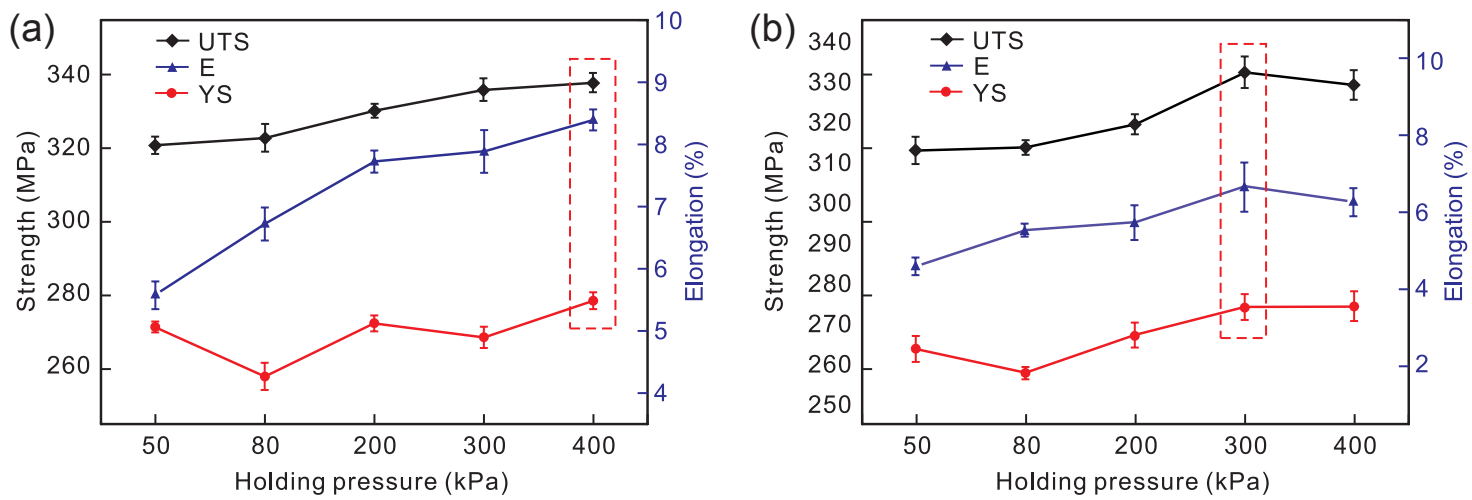

Fig. 8: Effect of holding pressure on mechanical properties of Area B (a) and Area C (b)

\section{Discussion}

It is obtained from the above results that the porosity of the samples is significantly reduced and the elongation is obviously improved with the increase of holding pressure, and the density of the samples increases due to the reduction of porosity. The porosity of Area B reaches the minimum at the holding pressure of $400 \mathrm{kPa}$, which is $60.4 \%$ lower than that at $50 \mathrm{kPa}$, while the elongation of Area B increases by $50 \%$ with the holding pressure increasing from 50 to $400 \mathrm{kPa}$. Similarly, the porosity of Area $\mathrm{C}$ reduces by $57.6 \%$ and the elongation improves by $81.3 \%$ when the holding pressure increases from 50 to $300 \mathrm{kPa}$.

Porosity defects mainly consist of gas pores and shrinkage cavities. The formation of gas pores is generally because that as the alloy solidifies, the solubility of hydrogen in the alloy melt drops rapidly, causing hydrogen to precipitate and form gas pores ${ }^{[19]}$. The generation of gas pores is closely related to the amount of hydrogen and impurities in the melt and the level of applied pressure ${ }^{[20,21]}$. In this experiment, the content of hydrogen and impurities in the melt can be reduced greatly by refining and degassing processes, therefore the applied pressure is the key factor affecting the formation of gas pores of the alloy. Based on the principle of pressure balance during the solidification of alloys, D. M. Stefanescu et al. ${ }^{[22]}$ established a theoretical model of gas pores formation as shown in Eq. (2), where the components on the left side of the equation are driving forces for the formation of gas pores and those on the right side are the inhibiting forces. Enhancing the holding pressure $P_{0}$ is equivalent to increasing the inhibiting force for the generation of gas pores, making them more difficult to form:

$$
P_{\mathrm{G}}+P_{\mathrm{shr}}=P_{0}+P_{\mathrm{st}}+P_{\text {exp }}+P_{\gamma}
$$

where $P_{\mathrm{G}}$ is the sum of the local pressure in the mushy zone and $P_{\text {shr }}$ is the negative pressure which resists the shrinkage induced flow, $P_{0}$ is the holding pressure applied, $P_{\text {st }}$ is the metallostatic pressure, $P_{\exp }$ is the expansion pressure due to phase transformation, and $P_{\gamma}$ is the surface tension on the pore.

Figure 9 shows the microstructures of Area B at the holding pressure of 50 and $400 \mathrm{kPa}$. As can be seen obviously, there are many shrinkage cavities (indicated by the red arrows) in the alloy when the holding pressure is $50 \mathrm{kPa}$. The shrinkage cavities exist among dendrites and distribute along the dentrite 
arms, and are mainly induced by insufficient inter-dendritic feeding ${ }^{[14]}$. It is generally believed that the dendrite arms begin to aggregate and form a three-dimensional grid when the solid fraction reaches $70 \%$ during the solidification of alloys ${ }^{[23]}$. The feeding channels among the dendrites become narrower and the resistance of feeding increases with the growth of dendrites, which makes it difficult to feed among dendrites. Some researchers have found that the effect of interdendritic feeding will improve after increasing the holding pressure ${ }^{[8,24,25]}$. According to the study of solidification and shrinkage characteristics and models of vacuum differential pressure casting by Qingsong Yan et al. ${ }^{[26]}$, the inter-dendritic feeding speed mainly depends on the holding pressure during crystallization solidification (which is equivalent to the crystallization holding pressure in APC). The application of higher holding pressure can lead to faster intergranular feeding speed, better feeding effect, and thus the denser solidification structure $^{[24]}$.

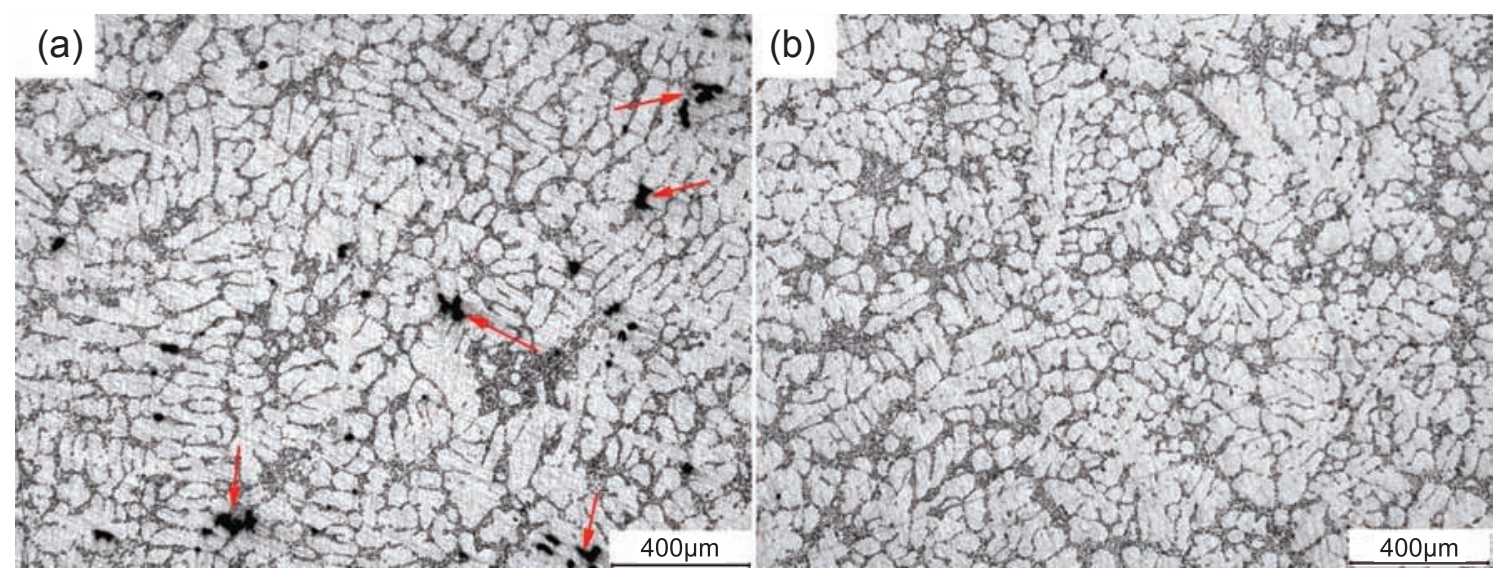

Fig. 9: Microstructures of Area B at $50 \mathrm{kPa}$ (a) and $400 \mathrm{kPa}$ (b)

The inter-dendritic feeding models under low and high pressures are shown in Fig. 10. The feeding force is weak when the holding pressure is low, so that some feeding channels are too narrow for the alloy melt to pass through. However, after applying a higher holding pressure, the interdendritic feeding strength can be increased significantly ${ }^{[26,27]}$. Therefore, the melt is able to pass through some narrow feeding channels among dendrites that it cannot pass at a low pressure. What's more, higher holding pressure can break some dendrites, thereby increasing the number of feeding channels. Based on the above reasons, the higher holding pressure can enhance the flowing and feeding ability of the alloy melt and reduce the generation of shrinkage cavities.
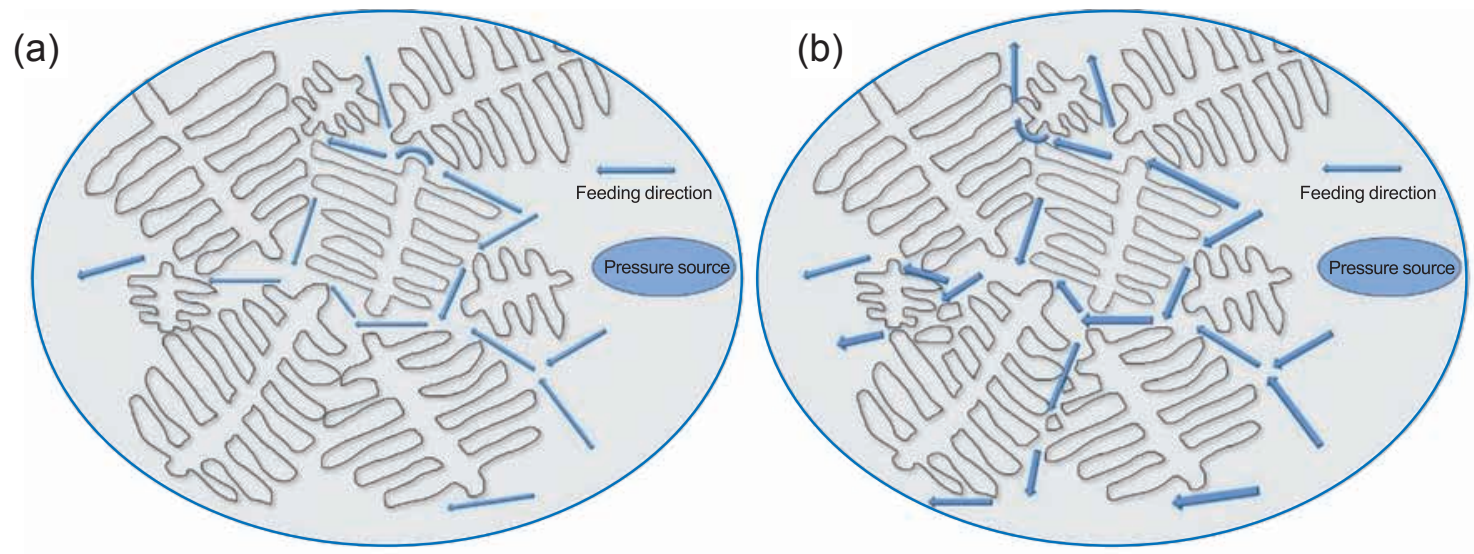

Fig. 10: Inter-dendritic feeding models at low pressure (a) and high pressure (b)

In addition to reducing the porosity defects and increasing the density of the alloy, the higher holding pressure can also increase the cooling rate of the alloy ${ }^{[8,25]}$. As can be seen from Fig. 6, as the holding pressure increases from 50 to $400 \mathrm{kPa}$, the cooling rate of Area B increases by $108.4 \%$. The cooling rate of Area $\mathrm{C}$ achieves the maximum at the holding pressure of $300 \mathrm{kPa}$, which is an increase of $100 \%$ compared to that at $50 \mathrm{kPa}$. During the APC process, a certain amount of air is stored in the mold cavity, and the mold used in APC tends to be airtight, resulting in an air gap between the mold wall and the shell formed after filling. What's more, the thermal conductivity of air is much lower than that of the mold, therefore the air gap 
seriously weakens the heat transfer between the melt and the mold ${ }^{[16,17]}$. As shown in Fig. 11, the efficiency of heat transfer is greatly reduced when the heat passes through the air gap. When a higher holding pressure is applied, the alloy melt and the shell are more closely adhered to the mold wall owing to the action of high holding pressure ${ }^{[9,28]}$. What's more, as can be seen in Fig. 11(b), the air gap becomes smaller, and the heat transfer efficiency is improved significantly. Therefore, the cooling rate of the alloy is greatly improved ${ }^{[25]}$. The increase of cooling rate can refine the grains and reduce the SDAS ${ }^{[29-31]}$, thereby improving the mechanical properties of the alloy ${ }^{[21,32]}$. In addition, the dendrites formed in the early stage of solidification can be broken under high pressure and drifted in the alloy melt, which will become new heterogeneous nucleation cores and make the grains refined ${ }^{[33]}$.
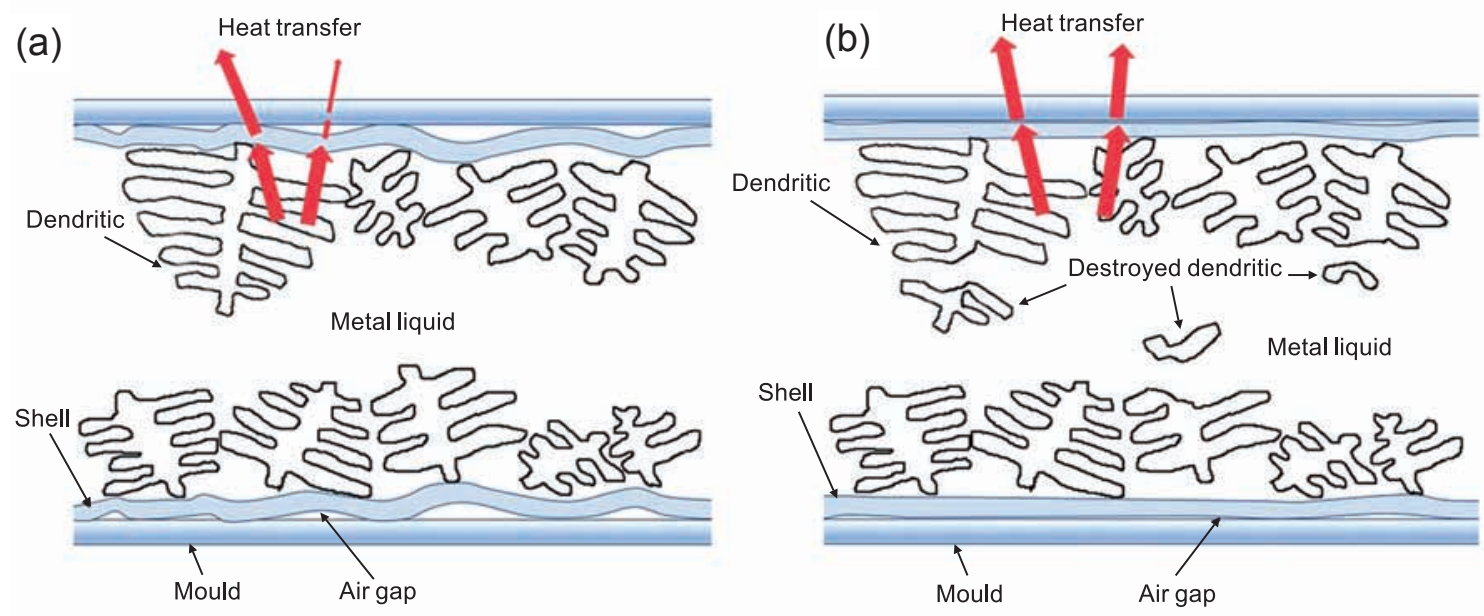

Fig. 11: Heat transfer models at low pressure (a) and high pressure (b)

It's precisely because of the increase of holding pressure that the cooling rate and the feeding ability of the alloy are improved, the microstructure of the alloy is optimized, and the porosity defects are reduced by about $60 \%$. As a result, the mechanical properties of the alloy are obviously improved ${ }^{[34]}$, especially the elongation.

However, it was noticed above that when the holding pressure increases to $400 \mathrm{kPa}$, the cooling rate of Area C decreases, and the microstructure and mechanical properties of Area $\mathrm{C}$ decline. The main reason for this phenomenon is that the excessive pressure improves the cooling rate of the gate portion greatly, causing it to solidify before Area C. The premature closing of the feeding channels causes the inability of the pressure to provide a continuous action on Area C. Therefore, the pressure has to be controlled within a reasonable range to get alloys with optimal microstructure and mechanical properties.

\section{Conclusions}

(1) As for the APC Al-Si alloy, the increase of holding pressure could greatly improve the feeding ability of the alloy, leading to an increase of the density. The increase of pressure from 50 to $300 \mathrm{kPa}$ could reduce the porosity of the alloy by $57.6 \%$, and improve the tensile strength and the elongation by $6.2 \%$ and $81.3 \%$, respectively.

(2) The increase of holding pressure could enhance the heat transfer efficiency between the alloy and the mold. With the increase of holding pressure from 50 to $300 \mathrm{kPa}$, the microstructure of the alloy becomes more homogeneous, and the SDAS is reduced by $19.8 \%$.

(3) Excessive holding pressure $(400 \mathrm{kPa})$ might lead the gate part to solidify before the main part of the sample and block the feeding channels. As a result, the SDAS becomes coarser and the mechanical properties decrease. Therefore, the pressure has to be controlled within a reasonable range during APC.

\section{References}

[1] Sui D S, Cui Z S, Wang R, et al. Effect of Cooling Process on Porosity in the Aluminum Alloy Automotive Wheel During LowPressure Die Casting. International Journal of Metalcasting, 2016, 10(1): 32-42.

[2] Reilly C, Duan J, Yao L, et al. Process Modeling of Low-Pressure Die Casting of Aluminum Alloy Automotive Wheels. The Minerals, Metals \& Materials Society, 2013, 65(9): 1111-1121.

[3] Mattia M, Giulio T, Franco B, et al. Impact behavior of A356 alloy for low-pressure die casting automotive wheels. Journal of Materials Processing Technology, 2009, 209(2): 1060-1073.

[4] Zhang B, Maijer D M, and Cockcroft S L. Development of a 3-D thermal model of the low-pressure die-cast (LPDC) process of A356 aluminum alloy wheels. Materials Science and Engineering: A, 2007, 464(1): 295-305.

[5] Long $\mathrm{H} \mathrm{C}$, Chen J H, Liu C H, et al. The negative effect of solution treatment on the age hardening of A356 alloy. Materials Science \& Engineering A, 2013 (566): 112-118.

[6] Xu C, Wang F, Hussain M, et al. Effect of Sc and Sr on the Eutectic Si Morphology and Tensile Properties of Al-Si-Mg Alloy. Journal of Materials Engineering \& Performance, 2017, 26(4): 1605-1613.

[7] Jiang W M, Fan Z T, Liu D J, et al. Correlation of microstructure with mechanical properties and fracture behavior of A356-T6 aluminum alloy fabricated by expendable pattern shell casting with vacuum and low-pressure, gravity casting and lost foam casting. Materials Science \& Engineering A, 2013, 560: 396-403. 
[8] Giulio T, Daniele C and Jovid R. Influence of Process Parameters and $\mathrm{Sr}$ Addition on the Microstructure and Casting Defects of LPDC A356 Alloy for Engine Blocks. Materials Science \& Technology, 2016, 32(6): 515-523.

[9] Zhang Y, Wu G H, Liu W C, et al. Effects of processing parameters and $\mathrm{Ca}$ content on microstructure and mechanical properties of squeeze casting AZ91-Ca alloys. Materials Science \& Engineering A, 2014, 595(3): 109-117.

[10] Maleki A, Niroumand B and Shafyei A. Effects of squeeze casting parameters on density, macrostructure and hardness of LM13 alloy. Materials Science \& Engineering A, 2006, 428(1): 135-140.

[11] Mohsen M, Henry Hu. Influence of applied pressure on microstructure and tensile properties of squeeze cast magnesium Mg-Al-Ca alloy. Materials Science \& Engineering A, 2011, 528(10): 3589-3593

[12] Jahangiri A, Marashi S P H, Mohammadaliha M, et al. The effect of pressure and pouring temperature on the porosity, microstructure, hardness and yield stress of AA2024 aluminum alloy during the squeeze casting process. Journal of Materials Processing Technology, 2017, 245: 1-6.

[13] Liu S G, Cao F Y, Zhao XY, et al. Characteristics of mold filling and entrainment of oxide film in low pressure casting of A356 alloy. Materials Science \& Engineering A, 2015, 626: 159-164.

[14] John A, Francis G M, Delphine C. The role of defects in the fracture of an Al-Si-Mg cast alloy. Materials Science \& Engineering A, 2005, 407(1): 322-329.

[15] Zhang H R, Zhang H, A fast pressure boosting method for mold Low Pressure Casting of aluminum alloy wheel. Chinese patent: CN 105618710A, 20160601.

[16] Wu X Y, Yun Y, Zhang H R, et al. Effect of holding pressure on microstructure and fracture behavior of low-pressure die cast A356-T6 alloy. Materials Research Express, 2017.

[17] Wu X Y, Zhang H R, Ma Zhen, et al. Effect of Holding Pressure on Microstructure and Mechanical Properties of A356 Aluminum Alloy. Journal of Materials Engineering \& Performance, 2018, 27(4): 483-491.

[18] Wang Q G, Apelian D and Lados D A. Fatigue behavior of A356/357 aluminum cast alloys. Part II - Effect of microstructural constituents. Journal of Light Metals, 2001, 1(1): 85-97.

[19] Ishita G, Suchandan K D and Nilratan C. An artificial neural network model to characterize porosity defects during solidification of A356 aluminum alloy. Neural Computing \& Applications, 2014, 25(3-4): 653-662.

[20] Geoffrey K S, Wang C M. Mechanisms of porosity formation during solidification: A theoretical analysis. Metallurgical Transactions B, 1993, 24(2): 349-364.

[21] Choong Do Lee. Effects of microporosity on tensile properties of A356 aluminum alloy. Materials Science \& Engineering A, 2007, 464(1): 249-254.
[22] Stefanescu D M, Catalina AV. Physics of microporosity formation in casting alloys - sensitivity analysis for Al-Si alloys International Journal of Cast Metals Research 2013, 24(3-4): $144-150$.

[23] Lee Y W, Chang E and Chieu C F. Modeling of feeding behavior of solidifying Al-7Si-0.3Mg alloy plate casting. Metallurgical Transactions B, 1990, 21(4): 715-722.

[24] Ghomashchi M R, Vikhrov A. Squeeze casting: an overview. Journal of Materials Processing Technology, 2000, 101(1): $1-9$.

[25] Li R X, Liu L J, Zhang L J, et al. Effect of Squeeze Casting on Microstructure and Mechanical Properties of Hypereutectic AlxSi Alloys. Journal of Materials Science \& Technology, 2017, 33(4): 404-410.

[26] Yan Q S, Yu H, Wei B K, et al. Solidification feeding behavior and model of vacuum counter-pressure casting technology. Chinese Journal of Nonferrous Metals, 2008, 18(6): 10511057.

[27] Zhao Z, Fan Z T. Influence on the Microstructures and Properties of A356 with Vibration Pressure in Lost Form Casting. Applied Mechanics \& Materials, 2014, 685: 7-10.

[28] Wei D, Wu S, Lü S, et al. Effects of rheo-squeeze casting parameters on microstructure and mechanical properties of AlCuMnTi alloy. Materials Science \& Engineering A, 2012, 538: 320-326.

[29] Eskin D G, Savran V I and Katgerman L. Effects of melt temperature and casting speed on the structure and defect formation during direct-chill casting of an $\mathrm{Al}-\mathrm{Cu}$ alloy. Metallurgical \& Materials Transactions A, 2005, 36(7): 19651976.

[30] Zhang L Y, Jiang $Y H, M a Z$, et al. Effect of cooling rate on solidified microstructure and mechanical properties of aluminium-A356 alloy. Journal of Materials Processing Tech, 2008, 207(1): 107-111.

[31] Leszek A D, Rafał M, Jerry H S, et al. Effect of cooling rate on the solidification behavior of $\mathrm{AC} \mathrm{AlSi}_{7} \mathrm{Cu}_{2}$ alloy. Journal of Materials Processing Technology, 2007, 191(1): 317-320.

[32] Carlos H C, Bengt I S. Casting defects and the tensile properties of an AISiMg alloy. Materials Science \& Engineering A, 1996, 220(1): 109-116.

[33] Jiang W M, Fan Z T, Liao D F, et al. Investigation of microstructures and mechanical properties of A356 aluminum alloy produced by expendable pattern shell casting process with vacuum and low pressure. Materials \& Design, 2011, 32(2): 926-934.

[34] Fabio G, Giulio T, Franco B. Doe applied to microstructural and mechanical properties of Al-Si-Cu-Mg casting alloys for automotive applications. Materials Science and Engineering: A, 2010, 527(15): 3536-3545. 